Special Issue of the 7th International Advances in Applied Physics and Materials Science (APMAS 2017)

\title{
Dry Sliding Wear Behaviour of Shot Peened TI6AL4V Alloys at Different Peening Times
}

\author{
Y. Yildiran Avcu ${ }^{a}$, O. YetiK ${ }^{a}$, H. KoçOĞLu ${ }^{b}$, E. Avcu ${ }^{c, *}$ And T. SinmazÇElik ${ }^{a}$ \\ ${ }^{a}$ Department of Mechanical Engineering, Kocaeli University, 41380, Kocaeli, Turkey \\ ${ }^{b}$ Department of Mechanical Engineering, Gebze Technical University, 41400, Gebze, Kocaeli, Turkey \\ ${ }^{c}$ Ford Otosan İhsaniye Automotive Vocational School, Kocaeli University, 41680, Kocaeli, Turkey \\ Titanium alloys have been extensively used in biomedical and aerospace applications, where the fatigue life \\ and tribological behaviour are important. Shot peening is a cold working mechanical surface treatment and has \\ been widely used to improve specifically the fatigue life of titanium alloys for the last decades. In this study, \\ the effect of shot peening on the dry sliding wear behaviour of Ti6Al4V alloy was investigated. Moreover, the \\ influences of peening time on the surface topography and the dry sliding wear behaviour of Ti6Al4V alloy were \\ discussed. Ball-on-disc tests were carried out to investigate tribological behaviour and a 3D optical profilometer \\ used to investigate the volume loss, the areal surface roughness, and the 3D surface topographies of shot peened \\ Ti6Al4V alloy before and after wear tests. The areal surface roughness values increased with increasing peening \\ time while dry sliding behaviour did not alter. The 3D surface roughness measurements of the peened and the \\ worn specimens revealed the topographical variations of the specimens.
}

DOI: 10.12693/APhysPolA.134.349

PACS/topics: dry sliding wear, shot peening, surface roughness, surface topography, Ti6Al4V

\section{Introduction}

Shot peening (SP) has been widely utilised to increase the fatigue strength of metal alloys $[1,2]$ and applied as a mechanical surface treatment to improve the surface properties of biomaterials [2]. SP is generally used owing to its capability to treat complex shaped components [3]. The surface of engineering components is repeatedly impacted by shot peening media consisting of steel shots during SP [3,4]. SP induces residual compressive stresses and leads to strain hardening on the surface and near surface of components [1-3]. The residual stress and the strain hardening induced by SP prevent crack initiation and propagation, which extends the fatigue life of components [1].

Titanium alloys have been prevalently used for aerospace, biomedical, chemical industry, and transportation applications owing to its superior mechanical properties and corrosion resistance $[2,5]$. Ti6Al4V is among the most widely used titanium alloys, which is a two-phase $(\alpha+\beta)$ titanium alloy [2]. The most important drawbacks of Ti6Al4V alloy are generally reported as poor fretting and wear resistance [3] due to its high surface energy which promotes wear in tribological applications [3]. Therefore, it is important to improve tribological behaviour of Ti6Al4V alloy, specifically under dry sliding wear. Thus, investigation of tribological behaviour of Ti6 Al4V alloy has gained increasing attention over the last decade [5-7].

*corresponding author; e-mail: avcuegemen@gmail.com
SP could be an effective way to enhance the surface and subsurface properties of titanium alloys and to modify their tribological behaviours. However, there are limited studies related to the effects of SP on the surface properties of titanium alloys, and the tribological behaviour of shot peened Ti6Al4V alloy has not been highlighted yet. In the present study, Ti6Al4V alloy specimens were peened at different peening times and dry sliding wear behaviour of the peened specimens was investigated in terms of friction coefficient, wear loss, volume loss, and $3 \mathrm{D}$ surface topography. The aim of the study is to investigate the effects of SP and specifically peening time on the dry sliding behaviour of Ti6Al4V alloy.

\section{Materials and methods}

\subsection{Materials}

Ti6Al4V alloy (grade 5) was supplied from TIMET (Titanium \& Medical \& Mining Company, Turkey). The chemical composition of the supplied alloy is in weight percent: $0.08 \mathrm{C}, 0.25 \mathrm{Fe}, 0.05 \mathrm{~N}, 0.20 \mathrm{O}, 5.50-6.75 \mathrm{Al}$, 3.5-4.5 V, 0.0150 H, and balance Ti. Stainless steel (SS) shots with diameter of $0.4-0.9 \mathrm{~mm}$ were used as SP media. The SEM image of a SS shot is given in Fig. 1a.

\subsection{Shot peening process}

SP was performed with a custom-designed shot peening test rig (Fig. 1b), in which SS shots were accelerated by high pressure air onto the surface of the Ti6Al4V specimens. In order to obtain grain refinement, SP was carried out under an air pressure of 7 bar for peening times of $5-15 \mathrm{~min}$. In addition, the distance and angle between the nozzle and the surface of Ti6Al4V specimens were kept constant as $20 \mathrm{~mm}$ and $90^{\circ}$, respectively. 


\subsection{Dry sliding wear test}

Dry sliding wear test were carried out by using a ball-on-disc tribometer (Nanovea Tribometer) in accordance with ASTM G99-95a. 100Cr6 balls were used as counterpart and the balls were pressed at $10 \mathrm{~N}$ against the specimens. The dry sliding velocity was adjusted as $0.1 \mathrm{~m} / \mathrm{s}$ and the tests were carried out with a dry sliding distance of $150 \mathrm{~m}$ and repeated for three times to obtain reproducibility. The coefficient of friction between the specimen and the ball was recorded and the variation of wear mass loss of the specimens was measured by weighing the specimens before and after the tests with an electronic balance of an accuracy of $\pm 0.1 \mathrm{mg}$. The volume loss of the specimens in cubic millimetres was examined via an optical profilometer (Nanovea PS50 Profilometer, NANOVEA). Finally, the specific wear rate of the specimens $K$, which is the wear loss per unit sliding distance $L$ and load $N$, was also investigated by using the following equation [8], in which $V$ is the wear volume as cubic millimetres $\left[\mathrm{mm}^{3}\right], L$ is the sliding distance as metres $[\mathrm{m}], N$ is the applied load $[\mathrm{N}]$ :

$$
K=V /(L N) \text {. }
$$

\subsection{Surface analysis of the specimens}

Areal surface roughness parameters in accordance with ISO 25178-2:2012 standard and surface topographies of the shot peened, unpeened, and worn specimens were analysed using an optical profilometer (Nanovea PS50, USA). The volume loss of the wear track was also measured by using an optical profilometry. The volume loss measurements then utilized to calculate the specific wear rate of the specimens described in the previous section.
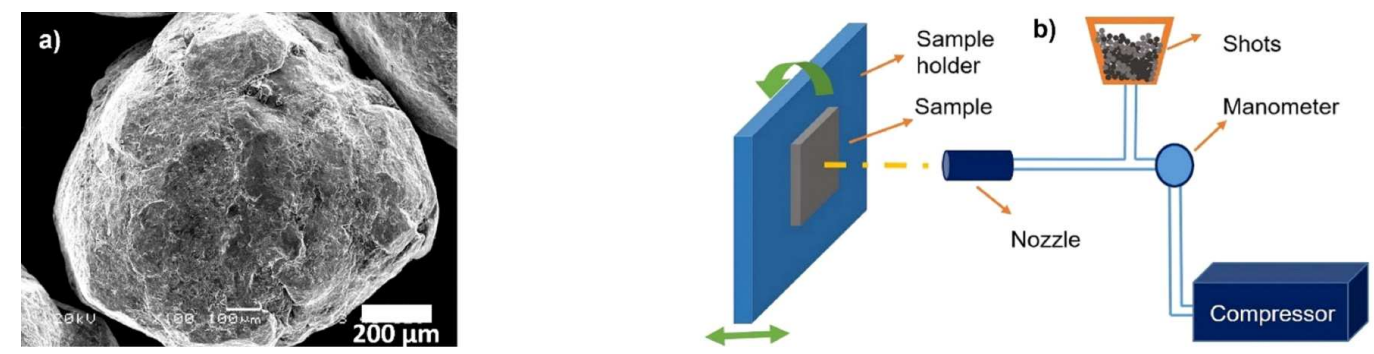

Fig. 1. (a) SEM image of SS shots, (b) schematic representation of of SP test rig.
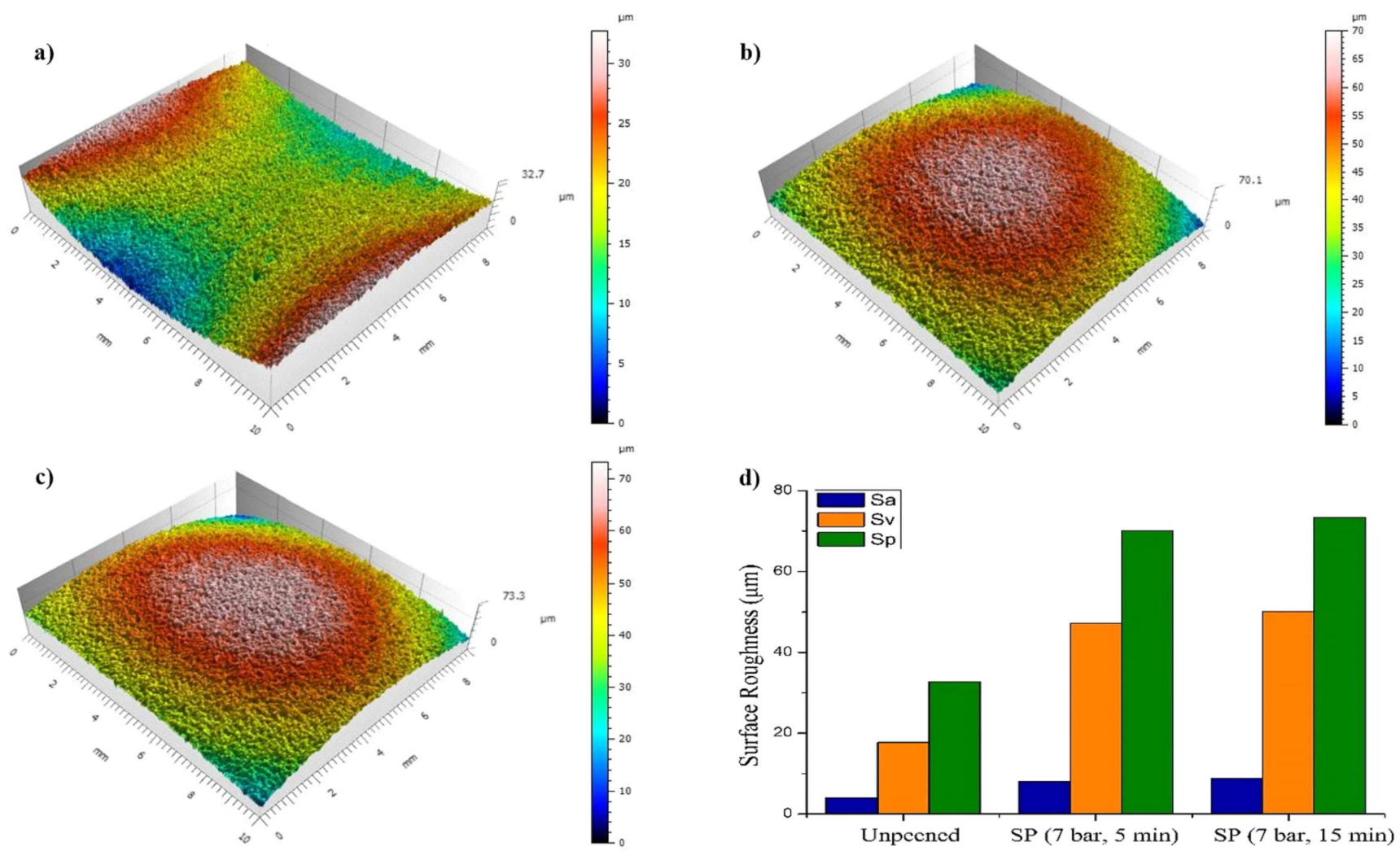

Fig. 2. The effect of shot peening on the 3D surface topographies: (a) unpeened, (b) 7 bar, 5 min, (c) 7 bar, 15 min, and (d) surface roughness of the Ti6Al4V. 


\section{Results and discussion}

\subsection{Variation of surface properties depending on $S P$}

The areal surface roughness values $\left(S_{a}, S_{v}\right.$, and $\left.S_{p}\right)$ of the specimens before and after SP are shown in Fig. 2. $S_{a}, S_{v}$, and $S_{p}$ correspond to the arithmetic mean of surface, the maximum height of valleys, and the maximum height of peaks, respectively, according to ISO 251782:2012 standard. The areal surface roughness parameters significantly increased with SP compared to the unpeened specimen (Fig. 2d). Deep craters appeared on the surface of the specimens after SP for peening time of 5 min due to the severe bombardments of shots (Fig. 2b). Large numbers of pile-ups are formed as well due to the metal flow around the craters. The heights of new pairs of peak and valley are apparently higher than that of the original surface (Fig. 2), leading to an increase in surface roughness. As the peening duration increased to $15 \mathrm{~min}$, the surface roughness tends to be stable as shown in Fig. 2c. It is reported that the surface roughness noticeably increased with increases in acceleration pressure and tends to reach a stable value [9]. The kinetic energy and velocity of the shots do not change depending on peening time, thus peening time does not influence surface roughness [9]. Menezes et al. reported that SP reduces surface roughness values in comparison to unpeened specimens [10]. Yildıran et al. reported that 3D surface topography is specifically varied with the acceleration pressure of shots. Height of peaks and depth of holes are increased sharply with the increasing pressure [11]. Xie et al. reported that after SP, the surfaces become rougher, which can be attributed to the impact of shots with high kinetic energy. The high energy of shots caused the deformation of surface [12].

\subsection{Dry sliding wear behaviour}

The variation of the coefficient of friction versus sliding distance for unpeened, SP (7 bar, $5 \mathrm{~min}$ ), and SP (7 bar, $15 \mathrm{~min})$ specimens are given in Fig. 3. A significant increase in the coefficient of friction at the beginning of the dry sliding was observed. After sliding distance of $60 \mathrm{~m}$, the coefficient of friction became stabilized. SP did not affect the coefficient of friction noticeably as seen in Fig. 3. The variations of volume loss, mass loss, and specific wear rate of unpeened specimen, and shot peened specimens at 7 bar for $5 \mathrm{~min}$, and at 7 bar for $15 \mathrm{~min}$ are given in Fig. 4. As clearly seen in Fig. 4a the volume loss slightly decreased with SP. The specific wear rate of the shot peened specimens also slightly decreased compared to the unpeened specimens as seen in Fig. 4b. Shot peening significantly improves the mechanical properties of surface and near surface of metals $[9,12]$ and specifically leads to significant increases in surface hardness [8]. Thus, it was expected significant decreases in coefficient of friction and specific wear rate due to the SP and eventually improvement of the wear resistance of Ti6Al4V alloy. However, shot peening very slightly enhanced the wear resistance of the alloy. Menezes et al. presented
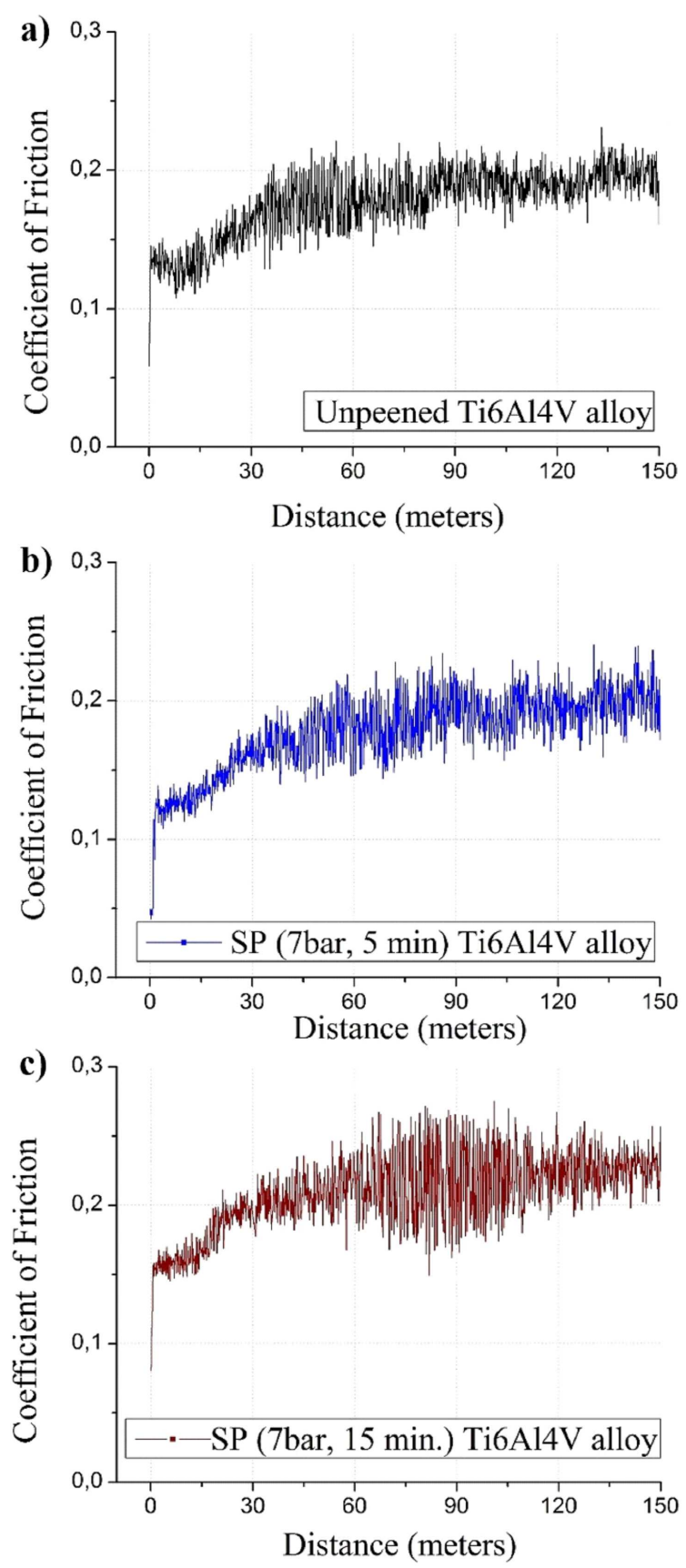

Fig. 3. Coefficient of frictions of (a) unpeened and (b) 7 bar, 5 min, and (c) 7 bar, 15 min SP specimens.

similar results and concluded that SP played an insignificant role in increasing wear resistance [10]. Liu et al. reported that nanocrystalline layer in Ti6Al4V can be fabricated via SP and the thickness of the deformation layer and the degree of grain refinement increase with an increase in pressure and peening duration [9]. The SP affected zone could be completely worn off during the dry sliding tests and this may cause the worn of unpeened alloy, which may be the underlying reason of the insignificant variation of specific wear rate. Therefore, dry sliding load and distance, as well as sliding velocity, should be 

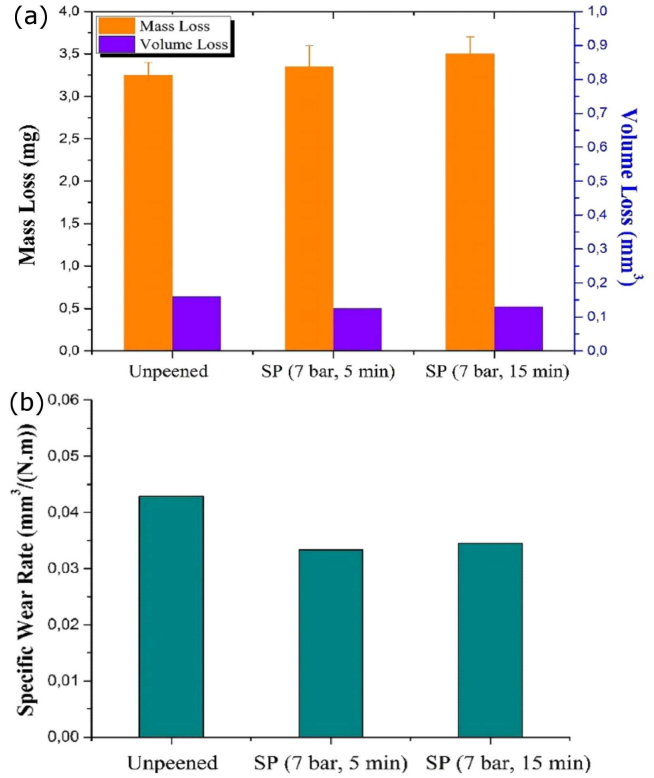

Fig. 4. Variations of (a) volume loss and mass loss, (b) specific wear rate.

carefully selected to prevent excessive wear during dry sliding. Otherwise, the wear results may reflect the wear behaviour of unpeened specimen and regions. Yan et al. reported that in both two body and impact abrasive wear

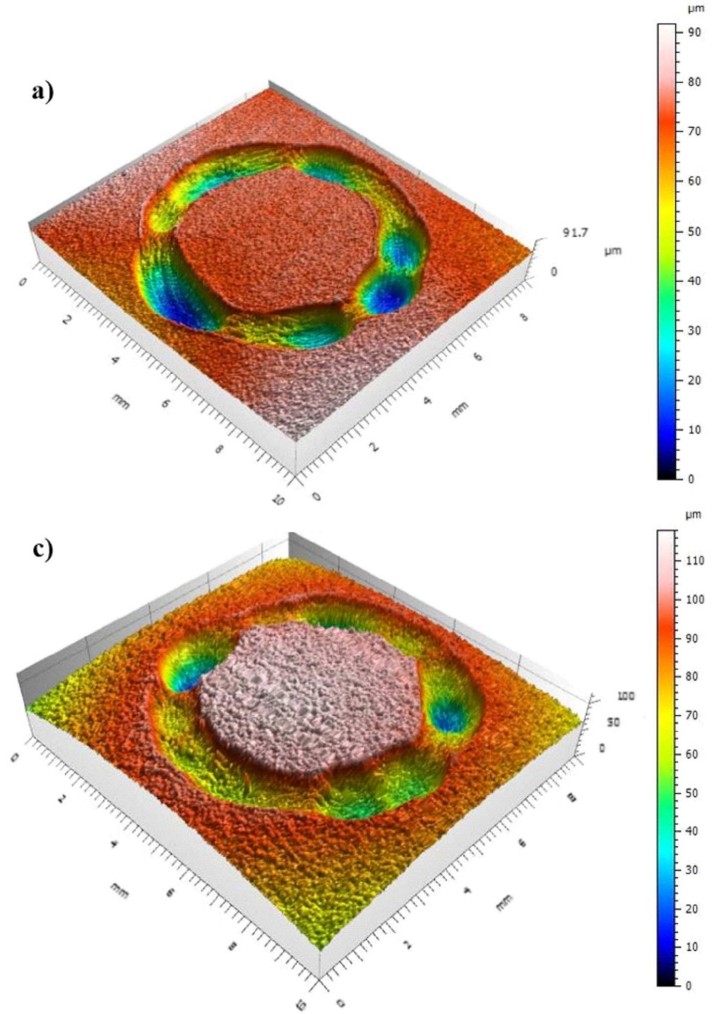

tests longer peening duration is not beneficial to increase the wear resistance of shot peened Hadfield steel [13]. In the present study, SP slightly increased the dry sliding wear resistance of Ti6Al4V alloy while increasing peening time does not contribute further improvement of the wear resistance.

\subsection{Surface properties after dry sliding wear}

The areal surface parameters $\left(S_{a}, S_{v}\right.$ and $\left.S_{p}\right)$ and 3D topographies of the worn surfaces of specimens are presented in Fig. 5. The $S_{a}, S_{v}$, and $S_{p}$ parameters did not remarkably increased with SP (7 bar, 5 min) while they increased dramatically with increasing peening time. The $3 \mathrm{D}$ topographies shed light on the volume loss and the wear damage depending on SP. As seen in Fig. 5b and Fig. 5c, the depth of the complete wear tracks significantly increased with SP. It is reported that the deformation layers in Ti6Al4V at different shot peening parameters possess different features such as roughness and grain refinement [9]. The plastic deformation is heterogeneous in the deformation layer and the heterogeneity increases with increases in pressure and peening duration [9]. Thus, SP could lead to undesired surface roughness which could provide possible crack initiation sites and may adversely affect the fatigue life and fretting wear behaviour as well [14]. Therefore, the surface properties of SP alloys should be considered and investigated in detail along with mechanical tests.

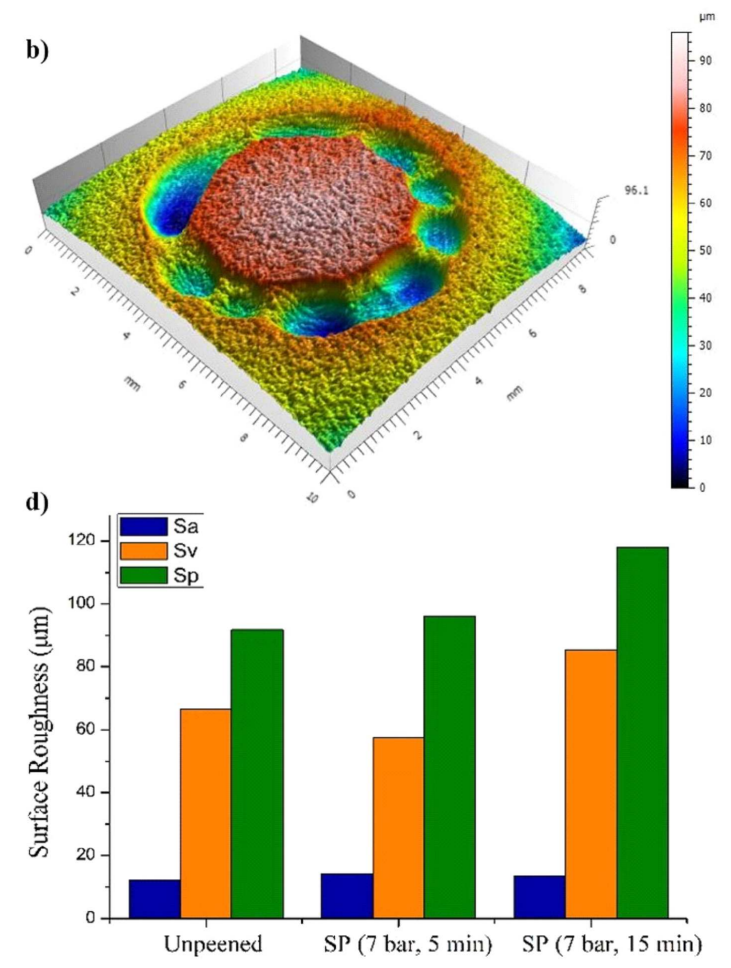

Fig. 5. 3D surface topographies: (a) unpeened, (b) 7 bar, $5 \mathrm{~min}$, (c) 7 bar, $15 \mathrm{~min}$, and (d) surface roughness values of the worn surfaces. 


\section{Conclusion}

The conclusions of the study are summarized as follows;

1. The areal surface parameters $\left(S_{a}, S_{p}\right.$, and $\left.S_{v}\right)$ significantly increased with SP and increased peening time.

2. The coefficient of friction slightly varied by SP and specific wear rate slightly decreased with increases in peening time.

3. The 3D topographies of the worn surfaces revealed the volume loss and wear damage depending on SP. The volume loss slightly decreased with SP.

In order to understand the effects of SP on the wear behaviour of Ti6Al4V alloy in detail: the changes of surface and subsurface morphology as well as microstructure depending on SP should be examined in detail. Thus, future research should be devoted to this.

\section{References}

[1] H. Lee, S. Mall, S. Sathish, Mater. Sci. Eng. A 390 $227(2005)$.
[2] A.A. Ahmed, M. Mhaede, M. Wollmann, L. Wagner, Appl. Surf. Sci. 363, 50 (2016).

[3] A. Amanov, I.-S. Cho, D.-E. Kim, Y.-S. Pyun, Surf. Coat. Technol. 207, 135 (2012).

[4] S. Dai, Y. Zhu, Z. Huang, Vacuum 125, 215 (2016).

[5] Z. Wu, Y. Xing, P. Huang, L. Liu, Surf. Coat. Technol. 309, 21 (2017).

[6] R. Niu, J. Li, Y. Wang, J. Chen, Q. Xue, Surf. Coat. Technol. 309, 232 (2017).

[7] A.K. Gujba, Z. Ren, Y. Dong, C. Ye, M. Medraj, Surf. Coat. Technol. 307, 157 (2016).

[8] E. Avcu, Tribol. Int. 110, 173 (2017).

[9] Y.G. Liu, M.Q. Li, H.J. Liu, Mater. Character. 123 83 (2017).

[10] M.R. Menezes, C. Godoy, V.T.L. Buono, M.M.M. Schvartzman, J.C. Avelar-Batista Wilson, Surf. Coat. Technol. 309, 651 (2017).

[11] Y. Yıldıran, E. Avcu, T. Sinmazçelik, Acta Phys. Pol. A 127, 984 (2015).

[12] L. Xie, L. Wang, C. Jiang, W. Lu, Surf. Coat. Technol. 244, 69 (2014).

[13] W. Yan, L. Fang, Z. Zheng, K. Sun, Y. Xu, Tribol. Int. 42, 634 (2009).

[14] A. Gujba, M. Medraj, Materials 7, 7925 (2014). 